\title{
Estimates and Spatial Distribution of Emissions from Sugar Cane Bagasse Fired Thermal Power Plants in Brazil
}

\author{
Ana Beatriz Kawashima1*, Marcos Vinícius Bueno de Morais ${ }^{1}$, \\ Leila Droprinchinski Martins'², Viviana Urbina3 ${ }^{3}$, Sameh Adib Abou Rafee1, \\ Maurício Nonato Capucim ${ }^{1}$ Jorge Alberto Martins ${ }^{1}$ \\ ${ }^{1}$ Department of Physics, Federal University of Technology-Parana, Londrina, Brazil \\ ${ }^{2}$ Department of Chemistry, Federal University of Technology-Parana, Londrina, Brazil \\ ${ }^{3}$ Department of Atmospheric Sciences, University of São Paulo, São Paulo, Brazil \\ Email: ${ }^{*}$ anak@alunos.utfpr.edu.br
}

Received 10 June 2015; accepted 21 August 2015; published 25 August 2015

\section{Abstract}

Sugar cane bagasse is one of the largest fuels used for electricity generation in Brazil and its usage has continuously increased to supply the energy demand. This paper presents emission inventory based on power plants burning sugar cane bagasse. The inventory involves the spatial distribution and the estimated flows for the following major pollutants: nitrogen oxides $\left(\mathrm{NO}_{\mathrm{x}}\right)$, particulate material (PM), carbon dioxide $\left(\mathrm{CO}_{2}\right)$ and total organic carbon (TOC). A total of 384 power plants were inventoried, representing a generated power of $9.9 \mathrm{GW}$, about $26 \%$ of the energy produced by thermal power plants sector. The plants are concentrated in two main poles: one of them in São Paulo State and nearby areas and the other one in coast of Brazilian Northeast. The limits proposed by the AP-42 Regulations of the US Environmental Protection Agency (USEPA) for the emission factors were applied. Additional emission factors identified in the scientific literature were also included in the analysis in order to assess the uncertainties associated to the estimative. The estimated emissions showed values in the range 16.0 - $20.5 \mathrm{Gg} \cdot \mathrm{year}^{-1}$ for NOx, 18.0 - 267.0 Gg.year-1 for MP and 20.5 - 26.7 $\mathrm{Tg}^{-y e a r}{ }^{-1}$ for $\mathrm{CO}_{2}$. The contribution of TOC showed a minor contribution around 10 - $20 \mathrm{Mg} \cdot y e a r^{-1}$. PM showed to be the most representative pollutant emitted by the thermal plants burning sugar cane bagasse, but with a large range of uncertainty. There is a high level of uncertainty associated to the preparation of cane as well as the use of collectors to control particulate emissions. The adequate control over all stages could reduce the bagasse ash content in $90 \%$ or more.

\section{Keywords}

Atmospheric Emissions Inventory, Air Pollution, Stationary Sources, Sugarcane Bagasse

\footnotetext{
${ }^{*}$ Corresponding author.
}

How to cite this paper: Kawashima, A.B., de Morais, M.V.B., Martins, L.D., Urbina, V., Rafee, S.A.A., Capucim, M.N. and Martins, J.A. (2015) Estimates and Spatial Distribution of Emissions from Sugar Cane Bagasse Fired Thermal Power Plants in Brazil. Journal of Geoscience and Environment Protection, 3, 72-76. http://dx.doi.org/10.4236/gep.2015.36012 


\section{Introduction}

The use of alternative fuel sources has strongly increased in the last decades in order to supply the energy demand of developing countries. However, this deliberate use of new forms of energy can produce an enormous amount of pollutants, which are emitted into the atmosphere. Therefore, there is a growing need for real actions in order to improve air quality, especially in urban and industrialized areas. In such areas, air pollution has become one of the main factors affecting people's quality life. In addition, the air pollution can cause several damage effects on the environment of the nearby areas [1] [2].

One of the decision-making tools used to represent chemical processes associated with air pollution and the associated impacts is the use of atmospheric models. Numerical air quality models approaches require information about emissions to feed the simulations for future scenarios studies. Therefore, build emission inventory appropriated to use in air quality modeling is necessary. Emission inventories represent the compilation of data and information that enable the characterization of pollution sources in time and space [3]. Through the use of modeling tools, the emission inventories of air pollutants can produce fundamental contributions to the development of scientific studies. For example, the impacts of energy sectors on air quality and health can be assessed in order to support public policies [4]-[6]. This study aims to quantify and georeference the thermal plants that use the sugarcane bagasse as fuel to the electricity generation in Brazil. In addition, an emission inventory properly prepared for modeling studies is also developed.

\section{Methodology}

\subsection{Domain Inventory}

Brazilian territorial unity is the inventory domain, covering about 8.5 millions of square kilometres. Brazil is the largest country in Latin America (Figure 1), with a total population of 200 million people, according to the World Bank's projection for 2015, representing about 50\% of the population of South America [7].

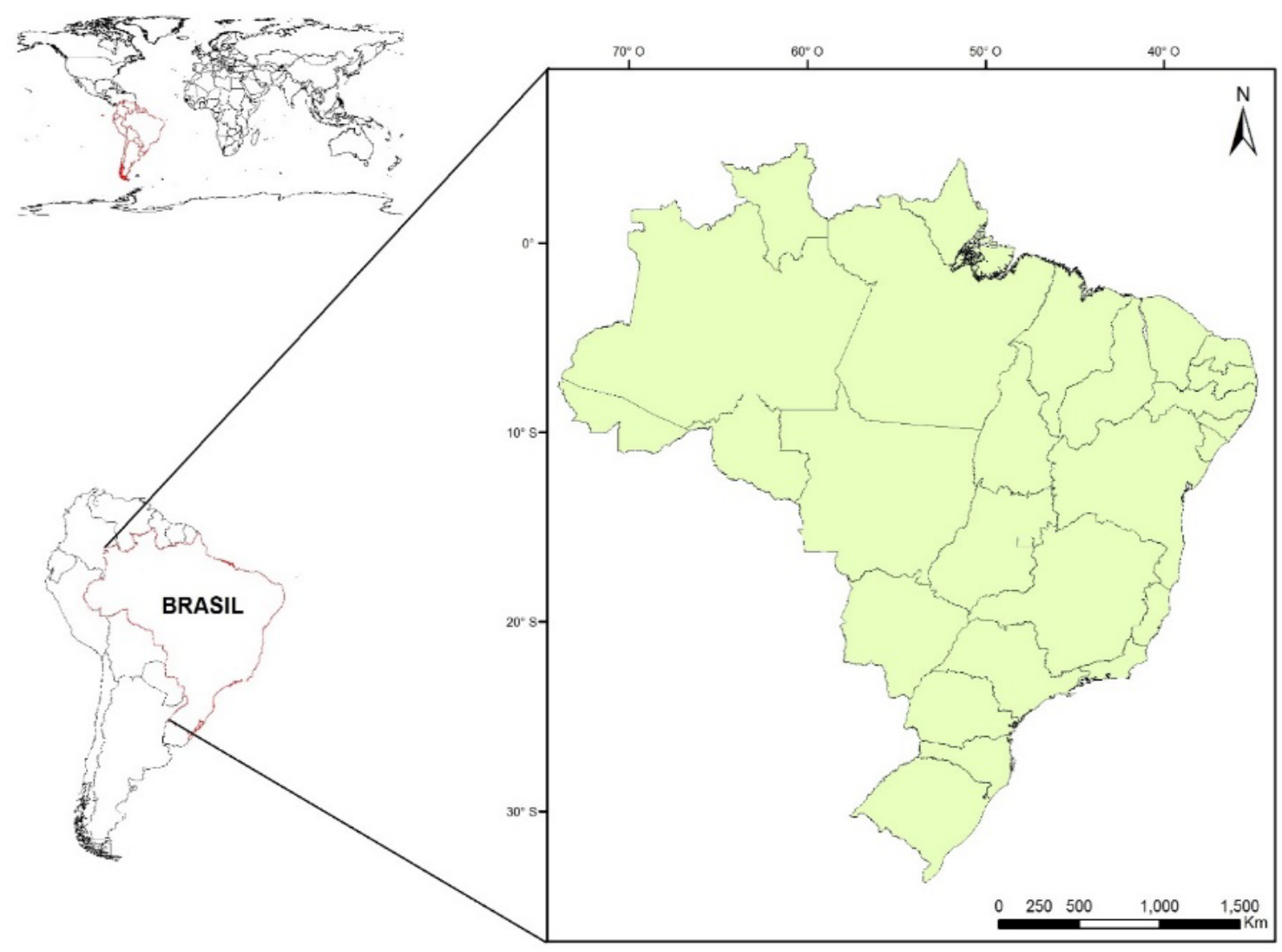

Figure 1. Geographical location of the study area, Brazil. 
The sugar cane bagasse is the cellulosic fiber of residual sugar and ethanol manufacturing process. The bagasse is the waste left after juice extraction of sugar cane, which has the capacity of power generation. In previous years, the bagasse was just a little widespread waste for energy purposes. However, with the increase of the global price of fossil fuels and the several droughts reaching most of Brazilian regions, the bagasse has become a great potential source of biomass for power generation in industrial sectors. Currently almost all of the sugarcane bagasse is utilized to generate electricity from its combustion. Every tonne of sugarcane results in about 0.3 tonne of bagasse, which is burned for electricity production to supply all energy needed in the mills [8]. Generally, the heating value varies 7 - $9 \mathrm{MJ} / \mathrm{kg}$ of sugarcane bagasse, with a moisture content between $45 \%$ and $55 \%$ of the mass. The Brazilian sugarcane industry and its associated thermal power plants are located mainly in São Paulo State and surrounding areas in the states of Paraná, Minas Gerais, Mato Grosso do Sul and Goiás, as well as all coastal area of the states of Alagoas, Pernambuco and Paraíba. Figure 2 illustrates the location of thermoelectric plants that uses the sugarcane bagasse. The 384 units of thermoelectric powered by sugarcane bagasse contributes with $9.9 \mathrm{GW}$ of total energy of the thermoelectric plants, which is about $26 \%$ of the energy produced by the sector (National Electrical Power Agency-ANEEL). It is the second ranked sector producing thermoelectric energy, behind the natural gas power plants. It is also the major representative sector using biomass for electricity production. As there is a marked expansion of sugarcane industrial park in Brazil, burning mechanisms and the associated emissions still need to be studied in greater depth so that the limits permitted values in this work should be seen only as a starting reference for further study.

\subsection{Characteristics of the Power Plants and Activity Rates}

The thermoelectric power plants that use sugarcane bagasse selected in this study are facilities that work with the burning bagasse to generate steam and, consequently, energy from the combustion processes. In general, the activity rate is an annual fuel consumption measurement that can be converted to the inventory user's convenience unit. The activity rate considered for this inventory was the Monitored Power (kWh.year ${ }^{-1}$ ) by ANEEL. This activity refers to a given period, usually one year. Considering that ethanol production in Brazil follow a very well defined seasonality, annual estimates was chosen as the more appropriate period for the use of sugar cane bagasse.

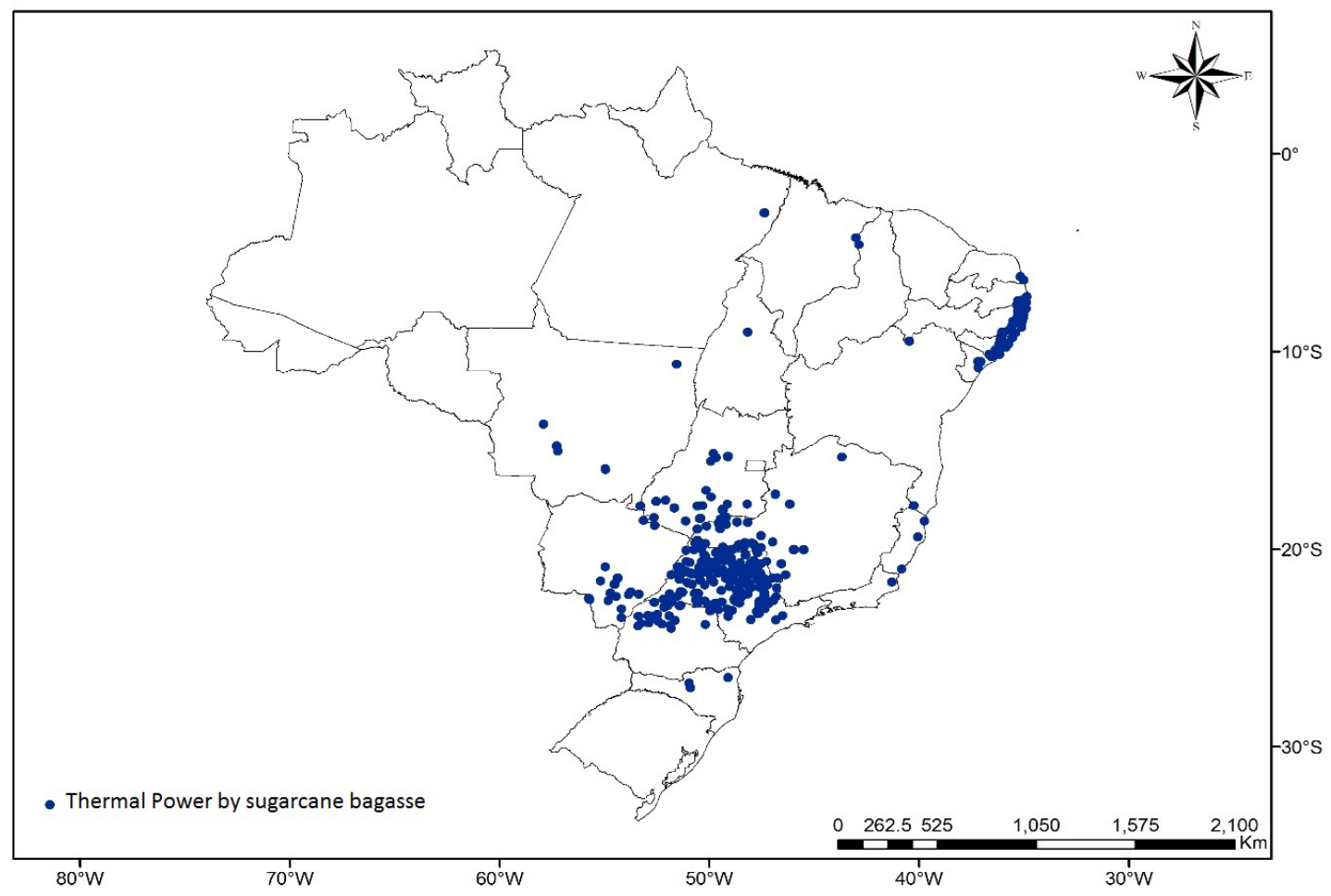

Figure 2. Distribution of thermal power by sugarcane bagasse. 


\subsection{Pollutants and Emission Factors}

The pollutants included in this emissions inventory are Total Particulate Matter (PM), Nitrogen Oxides $\left(\mathrm{NO}_{\mathrm{x}}\right.$ ), Carbon Dioxide $\left(\mathrm{CO}_{2}\right)$ and Total Organic Compound (TOC). For estimating biomass burning emissions, it is recommended the use of national emission factors. However, Brazilian private productive sectors are not obliged (and no enforced) to publish their atmospheric emissions. Therefore, in this study, the emissions are estimated based on the limits factors tracks published on the Compilation of Air Pollutant Emission Factors document (AP-42) [5] [6], and by Environmental Protection Agency of São Paulo (CETESB) [9] as an alternative means of comparison.

Emissions from thermal power plants that use the sugarcane bagasse will depend on the activity of the industrial unity and the emission factor associated with each pollutant. Thus, emissions can be estimated based on the following simplified equation [5] [6],

$$
E_{i j k t}=F E_{k} \times A_{i j k t}
$$

where $E_{i j k t}$ represents the total amount of pollutant $k$, delivered by the industry located at position $(i, j)$, during a certain time interval $t$ (one year in this study), while $F E_{k}$ is the emissions factor for pollutant $k$ and $A_{i j k t}$ is the activity of the industry located at position $(i, j)$ for the pollutant $k$, during the time interval $t$.

\section{Results}

The most common pollutant emitted during the burning of sugarcane bagasse is the $\mathrm{PM}$, while emissions of $\mathrm{NO}_{\mathrm{x}}$ and $\mathrm{SO}_{\mathrm{x}}$ are lower than those emitted from burning fossil fuels, due to bagasse lower content of sulfur and low temperature required during the combustion process. Moreover, auxiliary fuels can be used at the beginning of burning or when there is high moisture content in the sugarcane bagasse. In this case, the emissions of $\mathrm{NO}_{\mathrm{x}}$ and $\mathrm{SO}_{\mathrm{x}}$ may increase. Incorrect preparation of the cane or the inefficient burning can also increase the content of ash and emissions of $\mathrm{CO}$ and TOC. The emission factors adopted for the thermal power sugarcane bagasse are listed in Table 1. It is noted good level of agreement among the factors provided by AP-42 standard and those used by CETESB [9]. There were no emission factors for $\mathrm{CO}$ and $\mathrm{SO}_{\mathrm{x}}$, and factors were then assumed to be zero. In the case of $\mathrm{SO}_{\mathrm{x}}$ and TOC, experimental tests indicate that, under ideal conditions of burning, the emitted values can be negligible [10].

The contribution of emissions from bagasse-fired thermal power plants is only representative for $\mathrm{NO}_{\mathrm{x}}$, $\mathrm{PM}$ and $\mathrm{CO}_{2}$ (Table 1). For the $\mathrm{NO}_{\mathrm{x}}$ values $\left(16-21 \mathrm{Gg}\right.$ year ${ }^{-1}$ ) are equivalent to emissions by power plants, which operate on heavy fuel oil and natural gas, but they are lower than the contributions of plants using diesel and coal. Compared to vehicle emissions of $\mathrm{NO}_{\mathrm{x}}$, the contribution is not significant. In relation to the contribution

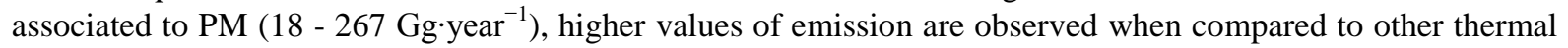
power sectors using fossil fuels. The values are also comparable to the emissions from vehicles. For the emissions of $\mathrm{CO}_{2}\left(20-27 \mathrm{Tg} \mathrm{year}^{-1}\right)$, the values are slightly higher them those recorded for the power plants burning fossil fuels, but the contribution showed to be no significant when compared to the vehicular emissions. When the estimative is based on emission factors adopted by CETESB [9], it is found a good level of agreement between the estimates. The most important contribution of emissions from bagasse-fired thermal power plants is the PM. In this case the contribution of the sector should be evaluated to beyond the estimates.

The spatial distribution is an important concern, once the power plants are concentrated mainly in two specific poles of the country, São Paulo and central part of the northeastern coast. It is important that modeling studies be carried to check the regional impacts of pollutants emitted by sugar cane sector and if itself can be considered as the major contribution to the observed concentration of air pollutants in these regions. In addition, the total amount calculated took into account emission factors ranges proposed by AP-42 Regulation of the US Environmental Protection Agency (USEPA) [11]. Although additional factors identified in the literature were also included for comparative purposes, and serve as parameters for evaluation of the uncertainty, more accurate emission factors and representative of Brazilian conditions are need.

\section{Conclusion}

The results of this study shows that atmospheric emissions from stationary sources to Brazil play a fundamental role in the concentration of air pollutants, and should be integrated in modelling studies of air quality, as well 
Table 1. Emission factors for sugarcane bagasse $\left(\mathrm{g} \cdot \mathrm{kWh}^{-1}\right)$.

\begin{tabular}{cccc}
\hline \multirow{2}{*}{ Pollutants } & \multicolumn{2}{c}{ EPA, 1996 $\left(\mathrm{g} \cdot \mathrm{kWh}^{-1}\right)$} & \multicolumn{2}{c}{$\begin{array}{c}\text { CETESB, 1999 } \\
\left(\mathrm{g} \cdot \mathrm{kWh}^{-1}\right)\end{array}$} \\
\cline { 2 - 4 } & Inferior Limit & Superior Limit & 0.27 \\
$\mathrm{NO}_{\mathrm{X}}$ & 0.28 & 0.36 & 3.51 \\
$\mathrm{PM}$ & 0.32 & 4.68 & - \\
$\mathrm{TOC}$ & 0.00023 & 0.00030 & 400 \\
$\mathrm{CO}_{2}$ & 359 & 468 & \\
\hline
\end{tabular}

Table 2. Emission total emissions for sugarcane bagasse $\left(\mathrm{Gg} \cdot \mathrm{year}^{-1}\right)$.

\begin{tabular}{ccc}
\hline Pollutants & EPA, $1996\left(\mathrm{Gg} \cdot \mathrm{year}^{-1}\right)$ & CETESB, $1999\left(\mathrm{Gg} \cdot \mathrm{year}^{-1}\right)$ \\
\hline $\mathrm{NO}_{\mathrm{X}}$ & $16.0-20.5$ & 15.4 \\
$\mathrm{PM}$ & $18.0-267.0$ & 200 \\
$\mathrm{TOC}$ & $0.01-0.02$ & - \\
$\mathrm{CO}_{2}$ & $20.5 \times 10^{3}-26.7 \times 10^{3}$ & $22.8 \times 10^{3}$ \\
\hline
\end{tabular}

as its impact on health and to define policies for an area.

\section{Acknowledgements}

This work received funding support from CNPq (National Counsel of Technological and Scientific Development, process 404104/2013-4), CAPES (Coordination for the Improvement of Higher Education Personnel) and Araucária Foundation.

\section{References}

[1] Wang, Y. (2010) The Analysis of the IMPACTS of energy Consumption on Environment And public Health in China. Energy, 35, 4473-4479. http://dx.doi.org/10.1016/j.energy.2009.04.014

[2] Guarieiro, L.L.N. and Guarieiro, A.L.N. (2013) Vehicle Emissions: What Will Change with Use of Biofuel? INTECH Open Access Publisher.

[3] EPA. U. S. Environmental Protection Agency (2011) Emission Inventory Improvement Program. Volume II: Introduction to the Stationary Point Source Emission Inventory Development. USEPA.

[4] IPCC. Intergovernmental Panel on Climate Change (2013) Summary for Policymakers. In: Stocker, T.F., Qin, D., Plattner, G.-K., Tignor, M., Allen, S.K., Boschung, J., Nauels, A., Xia, Y., Bex, V. and Midgley, P.M., Eds., Climate Change 2013: The Physical Science Basis. Contribution of Working Group I to the Fifth Assessment Report of the Intergovernmental Panel on Climate Change, Cambridge University Press, Cambridge and New York.

[5] EPA. U.S. Environmental Protection Agency (1996) AP-42: Compilation of Air Pollutant Emission Factors. Volume I: Stationary Point and Area Sources. Chapter 1: External Combustion Sources. 5th Edition, USEPA.

[6] EPA. U. S. Environmental Protection Agency (2000) AP-42: Compilation of Air Pollutant Emission Factors. Volume I: Stationary Point and Area Sources. Chapter 3: Stationary Internal Combustion Sources. 5th Edition, USEPA.

[7] BRASIL. IBGE, Ministério do Planejamento, Orçamento e Gestão. Instituto Brasileiro de Geografia e Estatística. Contagem Populacional. http://www.cidades.ibge.gov/

[8] Hofsetz, K. and Silva, M.A. (2012) Brazilian Sugarcane Bagasse: Energy and Non-Energy Consumption. Biomass and Bioenergy, 46, 564-573. http://dx.doi.org/10.1016/j.biombioe.2012.06.038

[9] Companhia de Tecnologia de Saneamento Ambiental. CETESB (1999) Relatório de Qualidade do Ar no Estado de São Paulo, 2000. CETESB, São Paulo.

[10] Werther, J., Saenger, M., Hartge, E.U., Ogada, T., and Siagi, Z. (2000) Combustion of Agricultural Residues. Progress in Energy and Combustion Science, 26, 1-27. http://dx.doi.org/10.1016/S0360-1285(99)00005-2

[11] EPA. U. S. Environmental Protection Agency (1995) AP-42: Compilation of Air Pollution Emission Factors. Volume I: Stationary Point and Area Sources. 5th Edition, U. S. Environmental Protection Agency, Office of Air Quality Planning and Standards, Research Triangle Park. 